\title{
Efficacy of deep biopsy for subepithelial lesions in the upper gastrointestinal tract
}

\author{
Rolandas Vaicekauskas ${ }^{1,2}$, Juozas Stanaitis ${ }^{1,2}$, Jonas Valantinas ${ }^{1,2}$ \\ ${ }^{1}$ Clinic of Gastroenterology, Nephrourology and Surgery, Faculty of Medicine, Vilnius University, Vilnius, Lithuania \\ ${ }^{2}$ Vilnius University Hospital Santariskiu Klinikos, Centre of Hepatology, Gastroenterology and Dietetics, Vilnius, Lithuania
}

Videosurgery Miniinv 2016; 11 (3): 192-199

DOI: $10.5114 /$ wiitm.2016.61429

\begin{abstract}
Introduction: Accurate diagnosis of subepithelial lesions (SELS) in the gastrointestinal tract depends on a variety of methods: endoscopy, endoscopic ultrasound and different types of biopsy. Making an error-free diagnosis is vital for the subsequent application of an appropriate treatment.

Aim: To evaluate the efficacy of deep biopsy via the endoscopic submucosal dissection (ESD) technique for SELs in the upper gastrointestinal tract.

Material and methods: It was a case series study. Deep biopsy via the ESD technique was completed in 38 patients between November 2012 and October 2014. Thirty-eight SELs in the upper gastrointestinal tract of varying size (very small $\leq 1 \mathrm{~cm}$, small $1-2 \mathrm{~cm}$ and large $\geq 2 \mathrm{~cm}$ ) by means of the ESD technique after an incision with an electrosurgical knife of the overlying layers and revealing a small part of the lesion were biopsied under direct endoscopic view.

Results: Deep biopsy via the ESD technique was diagnostic in 28 of 38 patients (73.3\%; 95\% CI: 59.7-89.7\%). The diagnostic yield for SELS with a clear endophytic shape increased to 91.3\%. An evident endophytic appearance of a subepithelial lesion, the mean number of biopsied samples $(6.65 \pm 1.36)$ and the total size in length of all samples per case $(19.88 \pm 8.07 \mathrm{~mm})$ were the main criteria influencing the positiveness of deep biopsy in the diagnostic group compared to the nondiagnostic one ( $p=0.001 ; p=0.025 ; p=0.008)$.

Conclusions: Deep biopsy via the ESD technique is an effective and safe method for the diagnosis of SELs especially with a clear endophytic appearance in a large number of biopsied samples.
\end{abstract}

Key words: deep biopsy, endoscopic submucosal dissection, subepithelial lesions, gastrointestinal stromal tumor.

\section{Introduction}

An accurate diagnosis of subepithelial lesions (SELS) in the gastrointestinal tract depends on a variety of methods: endoscopy, endoscopic ultrasound (EUS) and different types of biopsy. Making an error-free diagnosis is vital for the subsequent application of an appropriate treatment. Samples from the SELs for a histopathological evaluation should also be obtained.

\section{Aim}

The aim of our study was to evaluate the efficacy of deep biopsy via the endoscopic submucosal dissection (ESD) technique for SELs in the upper gastrointestinal tract.

\section{Material and methods}

It was a case series study. Deep biopsy via the endoscopic submucosal dissection technique in upper

\section{Address for correspondence}

Rolandas Vaicekauskas, Vilnius University Hospital Santariskiu Klinikos, Centre of Hepatology, Gastroenterology and Dietetics,

Santariškių g. 2, 08661 Vilnius, Lithuania, phone: +37 060062567, e-mail: rolandas.vaicekauskas@santa.lt 
gastrointestinal subepithelial lesions was completed in 38 patients between November 2012 and October 2014 at Vilnius University Hospital Santariskiu Clinics. The study protocol was authorized by the Vilnius Regional Research Ethics Committee with the Lithuanian Bioethics Committee, and written consent was obtained from all patients. The following inclusion criteria were met: (a) upper gastrointestinal tract solid subepithelial lesions of various sizes; (b) subepithelial lesions with a very prominent endophytic endoluminal growth pattern and an indistinct shape, not very prominent or exophytic growth pattern; (c) patients - age between 18 and 80; (d) no coagulation abnormalities (prothrombin $>50 \%$ and platelet count more than 50000 ), no use of any anticoagulant; (e) confirmed by the patient's written consent. Ex-

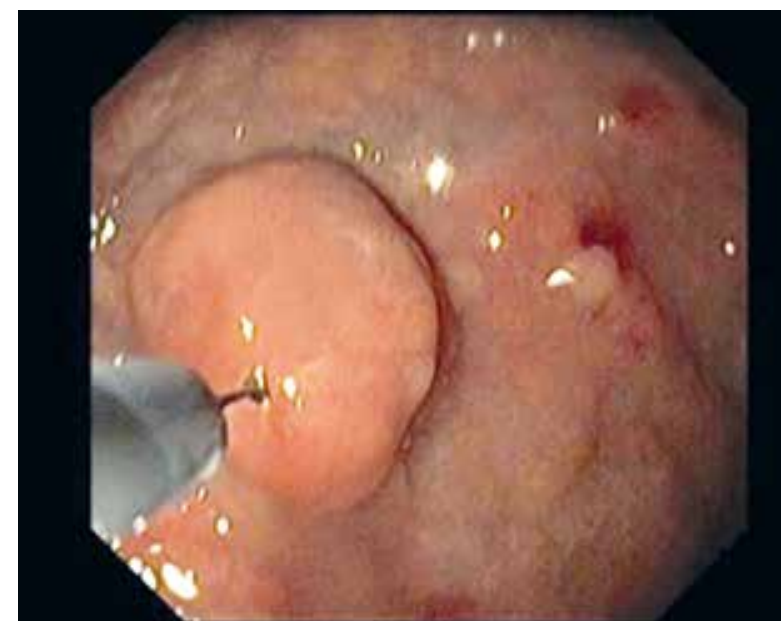

Photo 1. Incision of the overlying layers in the most prominent lesion part

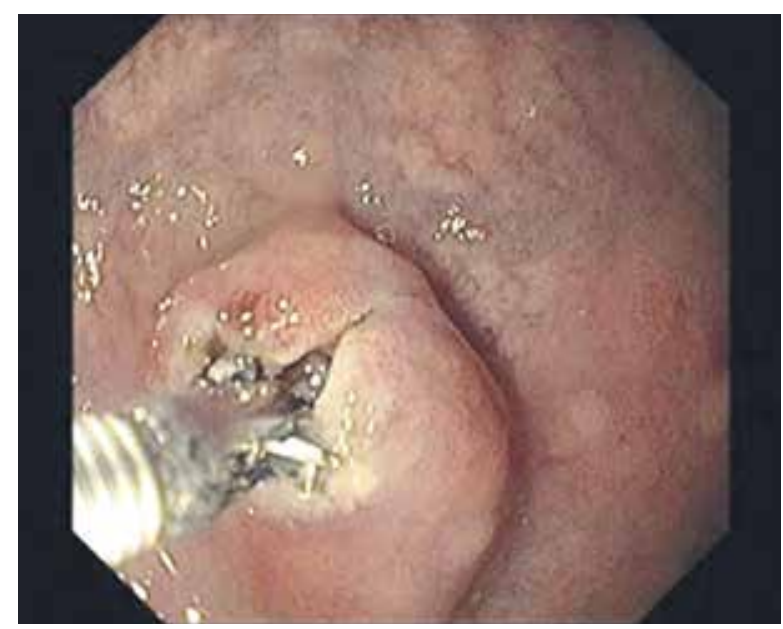

Photo 3. Biopsies with forceps under a direct endoscopic view clusion criteria were: (a) refusal to provide informed consent; (b) pregnancy; (c) severe comorbidities.

All procedures were performed on an inpatient basis and intravenous sedation. Endoscopic ultrasound was performed with radial and linear instruments (Olympus GF UE160-AL5 and GF 140P-AL5). The size, shape, layer of origin, echogenicity, location and presumptive diagnosis were recorded. If solid, deep biopsy via endoscopic submucosal dissection in the intramural subepithelial lesion was performed. Most of the procedures were carried out by one experienced endoscopist, specialized in performing ESD for other gastric lesions. Deep biopsy (Photos 1-4) was performed under the direct endoscopic view (GIF-1TQ160; Olympus, Tokyo, Japan) in various sizes of SELs (very small $\leq 1 \mathrm{~cm}$, small

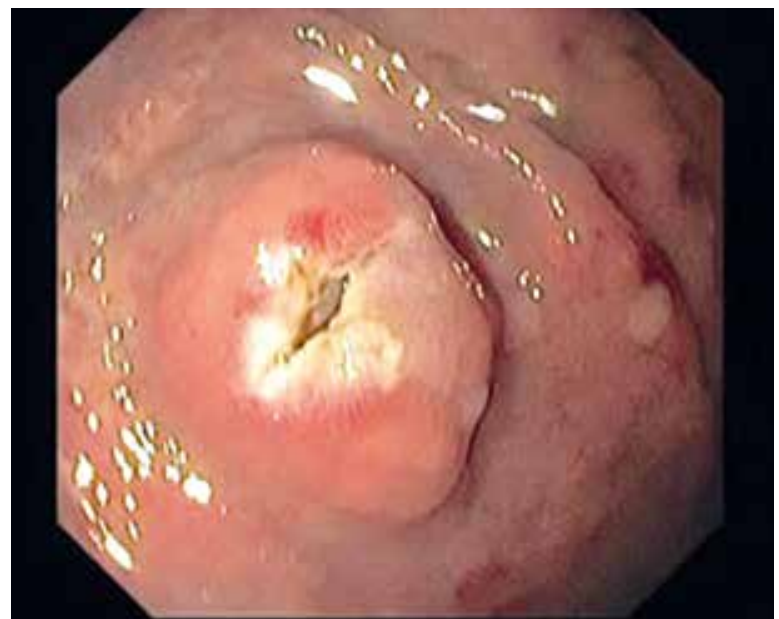

Photo 2. Dissection and disclose of the subepithelial lesion

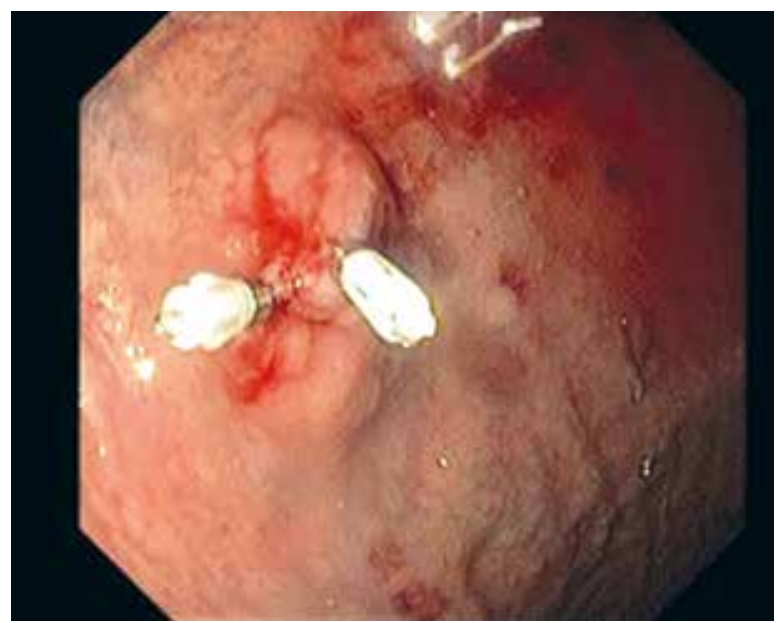

Photo 4. Clipping of the incision site 
1-2 $\mathrm{cm}$ and large $\geq 2 \mathrm{~cm}$ ). To obtain a better localization for biopsy in most cases, a transparent cap (Olympus, reusable straight distal attachment) was used. Incision of the overlying layers in the most prominent lesion part was done without the injection of epinephrine saline solution. Several types of electrosurgical knives were employed (Triangle tip KD-640L, Dual knife KD-650L, Hook knife KD-620LR; Olympus). The aim of the dissection was to reveal the subepithelial lesion and to create enough area for forceps to perform the direct biopsies. Multiple biopsies were obtained by means of a reusable large round cup with needle biopsy forceps FB-50K-1 and reusable round cup biopsy forceps FB-25K-1, Olympus. In most cases the incision site was not fully closed. After the biopsies a prophylactic endoscopic hemostasis was performed using the injection of epinephrine diluted with saline solution $1: 20$ 000, hot biopsies (AF 2423 DG, Alton), clipping (EZ Clip, HX-110QR, standard clip, Olympus) or, in a few cases, by ligating the lesion (ligating devise HX-21L-1, $13 \mathrm{~mm}$ loop, Olympus). For all patients an intravenous single esomeprazole infusion in a dosage of $40 \mathrm{mg}$ was prescribed the same day after the procedure and per oral later. In order to eliminate late post biopsy bleeding, a repeated endoscopic examination and full blood count were conducted the next day after the procedure, as was a telephone survey after 1 week. Deep biopsy complications were defined as indicating non-intensive bleeding (bleeding stopped spontaneously without hemostasis), intensive bleed-

Table I. Main characteristics of the study population

\begin{tabular}{|lc|}
\hline Parameter & Result \\
\hline Patients, $n$ & 38 \\
\hline Age (range) [years] & $58 \pm 12.4(26-82)$ \\
\hline $\begin{array}{l}\text { Gender, } n(\%): \\
\text { Male }\end{array}$ & $14(37)$ \\
\hline Female & $24(63)$ \\
\hline Mean size of SEL on EUS, range [mm] & $20.4 \pm 11.7(7-50)$ \\
\hline \begin{tabular}{l} 
Location, $n$ (\%): \\
\hline \begin{tabular}{l} 
Esophagus \\
\hline Stomach
\end{tabular}
\end{tabular} & $10(26 \%)$ \\
\hline Duodenum & $25(66 \%)$ \\
\hline
\end{tabular}

ing (bleeding requiring endoscopic hemostasis with epinephrine injection, coagulation, clipping or ligation) and perforation (free air visible on abdominal scan).

\section{Statistical analysis}

Acquired data were analyzed using SPSS version 17.0 for Windows and Microsoft Excel 2010. Continuous variables were expressed as mean \pm SD, and categorical variables were denoted as frequency (\%). Quantitative data were analyzed by the Mann-Whitney $U$ test, while categorical variables were compared between groups using the $\chi^{2}$ or Fisher's exact test. The histopathological values of gastrointestinal stromal tumor (GIST) between the deep biopsy and after the resection were compared by means of Wilcoxon's matched-pairs signed-rank test. A $p$-value of less than 0.05 was considered to be statistically significant.

\section{Results}

Deep biopsy via ESD technique for upper gastrointestinal tumors was performed in 38 patients. The main characteristics of the study population are summarized in Table I. Most of them were asymptomatic or had nonspecific symptoms unrelated to the lesions, but one had dysphagia. Biopsies were mostly taken from lesions located in the stomach ( $n=25,66 \%$ ), followed by a decreasing number in other locations: esophagus $(n=10,26 \%)$ and duodenum ( $n=3,8 \%)$. The endoscopic examination revealed the following characteristics of the lesions concerning the shape and appearance of overlaying mucosa: clear endophytic growth with distinct margins $(23 ; 60.5 \%)$ and with indistinct margins, not very prominent or exophytic growth pattern (15; $39.5 \%)$. The appearance of overlaying mucosa was normal in 33 (86.8\%) and ulcerated or with mucosal ulcers after a previous "bite-on-bite" biopsy in 5 (13.2\%). Only 1 case was diagnostic in 18 in whom biopsies according to the "bite-on-bite" technique were performed. Deep biopsy via the ESD technique was diagnostic in 28 of 38 patients $(73.3 \%$; $95 \% \mathrm{Cl}$ : 59.7-89.7\%). The diagnostic yield for SELs with the clear endophytic shape increased to $91.3 \%$.

The deep biopsy complications were: non-intensive bleeding 21 (55.3\%), intensive bleeding $2(5.3 \%)$ and perforation in 1 (2.6\%) case, which was suspected after nondiagnostic deep biopsy for the 
Table II. Factors affecting the deep biopsy effectiveness in nondiagnostic and diagnostic groups

\begin{tabular}{|c|c|c|c|}
\hline Parameter & Nondiagnostic & Diagnostic & $P$-value \\
\hline Patients, $n$ & 10 & 28 & \\
\hline \multicolumn{4}{|l|}{ Age [years]: } \\
\hline Mean \pm SD & $57.4 \pm 9.71$ & $57.96 \pm 13.41$ & \multirow[t]{2}{*}{0.539} \\
\hline Median (range) & $54.5(45-76)$ & $61(26-82)$ & \\
\hline $\begin{array}{l}\text { Age }>60 \text { years, } \\
n(\%)\end{array}$ & $4(40)$ & $15(53.6)$ & 0.714 \\
\hline \multicolumn{4}{|l|}{ Gender, $n(\%)$ : } \\
\hline Male & $5(50)$ & $9(32.1)$ & \multirow[t]{2}{*}{0.449} \\
\hline Female & $5(50)$ & 19 (67.9) & \\
\hline \multicolumn{4}{|l|}{ Localization, $n$ (\%): } \\
\hline Esophagus & $2(20)$ & $8(28.6)$ & \multirow[t]{3}{*}{1} \\
\hline Stomach & $7(70)$ & $18(64.3)$ & \\
\hline Duodenum & $1(10)$ & $2(7.1)$ & \\
\hline \multicolumn{4}{|l|}{ Shape, $n(\%)$ : } \\
\hline Prominent & $2(20)$ & $21(75)$ & \multirow[t]{2}{*}{0.001} \\
\hline Non-prominent & $8(80)$ & $7(25)$ & \\
\hline \multicolumn{4}{|c|}{ Size EUS [mm], $n(\%)$ : } \\
\hline$\leq 10$ & $4(40)$ & $5(17.9)$ & \multirow[t]{3}{*}{0.232} \\
\hline $11-19$ & $4(40)$ & $10(35.7)$ & \\
\hline$\geq 20$ & $2(20)$ & $13(46.4)$ & \\
\hline \multicolumn{4}{|l|}{ Layer, $n$ : } \\
\hline $2^{\text {nd }}$ & 2 & 3 & \multirow[t]{4}{*}{0.406} \\
\hline $3^{\text {rd }}$ & 3 & 6 & \\
\hline $4^{\text {th }}$ & 4 & 18 & \\
\hline Unknown & 1 & 1 & \\
\hline \multicolumn{4}{|c|}{ Number of biopsies: } \\
\hline Mean \pm SD & $5.33 \pm 1.5$ & $6.65 \pm 1.36$ & \multirow[t]{2}{*}{0.025} \\
\hline Median (range) & $5(2-7)$ & $7(4-10)$ & \\
\hline \multicolumn{4}{|c|}{ Total biopsy size [mm]: } \\
\hline Mean $\pm S D$ & $11.22 \pm 6.57$ & $19.88 \pm 8.07$ & \multirow[t]{2}{*}{0.008} \\
\hline Median (range) & $12(2-21)$ & $20(4-35)$ & \\
\hline \multicolumn{4}{|c|}{ Complications, $n(\%)$ : } \\
\hline No bleeding & $2(20)$ & $12(42.9)$ & \multirow[t]{4}{*}{0.178} \\
\hline $\begin{array}{l}\text { Non-intensive } \\
\text { bleeding }\end{array}$ & $6(60)$ & $15(53.6)$ & \\
\hline $\begin{array}{l}\text { Intensive } \\
\text { bleeding }\end{array}$ & $1(10)$ & $1(3.6)$ & \\
\hline Perforation & $1(10)$ & $0(0)$ & \\
\hline
\end{tabular}

lesion with exophytic growth pattern and confirmed as free air visible on abdominal scan. Urgent surgery was performed. The patient follow-up was performed with an upper endoscopy the next day after biopsy and the telephone survey was conducted after 1 week. There were only 2 cases of non-severe bleeding (Forrest IIB) from the deep biopsy site on the next day after the procedure, and no complications were noted at 1 week.

Factors affecting the deep biopsy effectiveness in nondiagnostic and diagnostic groups are summarized in Table II. An evident endophytic appearance of the subepithelial lesion, the mean number of biopsied samples $(6.65 \pm 1.36)$ and the total size in length of all samples per case $(19.88 \pm 8.07 \mathrm{~mm})$ were the main criteria influencing the positiveness of deep biopsy. The pathological diagnoses are shown in Table III. Most of the cases were leiomyomas, followed by GISTs. The deep biopsy was unable in all cases to correctly identify the mitotic count and the risk of GISTs because of insufficient high power fields (HPF), revealed by the pathological examination of biopsied specimens (Tables IV and V).

\section{Discussion}

An accurate diagnosis of subepithelial lesions in the gastrointestinal tract depends on a variety of methods: endoscopy, EUS and different types of biopsy. Establishing an accurate diagnosis is vital for the subsequent application of appropriate treatment or follow-up. Thus, it is not enough to perform only EUS [1]. According to this study in $42.9 \%$ of cases

Table III. Pathological results of deep biopsy

\begin{tabular}{|lc|}
\hline Histology & Result, $n$ (\%) \\
\hline GIST & $9(23.7)$ \\
\hline Leiomyoma & $13(34.2)$ \\
\hline Lipoma & $2(5.3)$ \\
\hline Ectopic pancreas & $2(5.3)$ \\
\hline Brunner's gland hyperplasia & $1(2.6)$ \\
\hline $\begin{array}{l}\text { Mesenchymal tumor with low } \\
\text { malignant potential }\end{array}$ & $1(2.6)$ \\
\hline Diagnostic & $28(73.7)$ \\
\hline Non-diagnostic & $10(26.3)$ \\
\hline Total & $38(100)$ \\
\hline
\end{tabular}


Table IV. Prediction of GIST risk after deep biopsy and resected specimen

\begin{tabular}{|c|c|c|c|c|c|c|c|c|}
\hline \multirow[t]{2}{*}{ Location } & \multirow{2}{*}{$\begin{array}{l}\text { Size } \\
\text { EUS } \\
{[\mathrm{mm}]}\end{array}$} & \multicolumn{3}{|c|}{ After deep biopsy } & \multirow{2}{*}{$\begin{array}{c}\text { Size } \\
\text { postoperative } \\
{[\mathrm{mm}]}\end{array}$} & \multicolumn{3}{|c|}{ After resection } \\
\hline & & $\begin{array}{l}\text { Mitotic } \\
\text { rate }\end{array}$ & HPF & $\begin{array}{c}\text { Risk } \\
\text { (Miettinen\&Lasota) }\end{array}$ & & $\begin{array}{l}\text { Mitotic } \\
\text { rate }\end{array}$ & HPF & $\begin{array}{c}\text { Risk } \\
\text { (Miettinen\&Lasota) }\end{array}$ \\
\hline Duodenum & 35 & 1 & 39 & - & 37 & 2 & 50 & Low \\
\hline Stomach & 24 & 0 & 23 & - & 15 & 1 & 50 & None \\
\hline Stomach & 10 & 0 & 3 & - & 8 & 4 & 50 & None \\
\hline Stomach & 40 & 2 & 45 & - & 50 & 5 & 50 & Very low \\
\hline Stomach & 11 & 3 & 50 & None & 12 & 15 & 50 & None \\
\hline Duodenum & 15 & 0 & 11 & - & 14 & 1 & 50 & None \\
\hline Stomach & 31 & 0 & 48 & - & 25 & 4 & 50 & Very low \\
\hline Stomach & 45 & 1 & 40 & - & - & - & - & - \\
\hline Stomach & 27 & 2 & 50 & Very low & 33 & 7 & 50 & Moderate \\
\hline
\end{tabular}

Table V. Prediction of GIST risk after deep biopsy and resected specimen

\begin{tabular}{|lccc|}
\hline Variable & Biopsy & $\begin{array}{c}\text { After } \\
\text { resection }\end{array}$ & P-value \\
\hline $\begin{array}{l}\text { Size } \\
\text { (EUS vs. resection) }\end{array}$ & $23.71 \pm 12.05$ & $23 \pm 15.38$ & 0.734 \\
\cline { 2 - 4 } & $24(10-40)$ & $15(8-50)$ & \\
\hline Mitotic rate & $0.86 \pm 1.22$ & $4.57 \pm 4.86$ & 0.017 \\
\cline { 2 - 4 } & $0(0-3)$ & $4(1-15)$ & \\
\hline HPF & $31.29 \pm 18.96$ & $50 \pm 0$ & 0.028 \\
\hline $39(3-50)$ & $50(50-50)$ & \\
\hline
\end{tabular}

in which preoperative EUS was performed but without a histological examination after surgery, they appeared to be benign. It seems that preoperative biopsy of SEL should be performed. However, there is no single management algorithm of these lesions.

Several recommendations regarding the management of SELS could be produced. The European Gastrointestinal Endoscopy Society (ESGE) suggests that esophageal SELS are rarely malignant and lesions $<2 \mathrm{~cm}$ should not be biopsied, unless they are large and/or suspicious of malignancy. The management of gastric SELs depends on the lesion size, resectability and the patients' general health state being adequate to undergo the surgical procedure. If the lesion is small $(<2 \mathrm{~cm})$, it is unlikely to be affected by EUS-fine-needle aspiration (FNA) or EUS-Trucut biopsy (TCB), and surveillance seems to be the best option. If the gastric hypoechoic SEL is $>2 \mathrm{~cm}$, in three quarters of cases it will be GIST. The diagnostic yield of biopsy methods to determine the final lesion etiology and the mitotic index being low, the laparoscopic wedge resection of SEL in most patients is a safe option unless the patient is a poor surgical candidate or the tumor is located in areas difficult to resect, such as the cardia. EUS-FNA or EUS-TCB should be performed for a suspected unresectable GIST in which primary treatment with tyrosine kinase inhibitors is considered [2]. On the other hand, the European Society for Medical Oncology (ESMO)/European Sarcoma Network Working Group recommends that if the SEL has been confirmed histologically as a GIST and even if it is less than $2 \mathrm{~cm}$, it should be surgically resected or, depending on the patient's age, life expectancy, and comorbidities, can be followed up. These small GISTs are actually of low risk; nevertheless, their clinical significance, progression to a higher risk level and follow-up rate are unclear. When the SELs are $<2 \mathrm{~cm}$ and the etiology is unknown, the standard approach will be that of endoscopic ultrasound with a subsequent annual follow-up, reserving excision for patients whose tumor increases in size or become symptomatic [3]. There is no strong evidence to establish how often a follow-up examination should be performed. Both guidelines emphasize that SELS $>2$ $\mathrm{cm}$ are associated with higher risk, especially if they are in the stomach or hypoechogenic; in this case resection should be the first choice of management.

In the examination of SELs the most important aim is to differentiate GISTs from other hypoecho- 
genic SELs. The gold standard to do this is with the help of an immunohistochemical analysis of biopsied specimens. Several biopsy methods for this purpose could be applied, such as: A) endoscopy controlled biopsies with small and large-capacity forceps using a bite-on-bite technique; B) "unroofing" and "key- hole" techniques; C) "deep" endoscopy controlled biopsies using the endoscopic submucosal dissection technique or mucosal-incision assisted biopsy (MIAB); D) EUS-guided, such as single-incision needle-knife biopsy (SINK), FNA and TCB. The diagnostic yield proved to vary widely: $17-100 \%$ (Table VI). In

Table VI. Results of deep biopsy in other studies

\begin{tabular}{|c|c|c|c|c|c|c|c|c|}
\hline \multirow[t]{2}{*}{ Study } & \multirow[t]{2}{*}{ Study design } & \multirow{2}{*}{$\begin{array}{c}\text { Lesions, } \\
n\end{array}$} & \multirow{2}{*}{$\begin{array}{l}\text { Sampling } \\
\text { technique }\end{array}$} & \multirow[t]{2}{*}{ Forceps type } & \multirow{2}{*}{$\begin{array}{c}\text { Complication } \\
\text { rate } \\
n / \%\end{array}$} & \multicolumn{3}{|c|}{ Specimens } \\
\hline & & & & & & $\begin{array}{c}\text { Diagnostic } \\
\%\end{array}$ & $\begin{array}{l}\text { GIST } \\
\text { mitotic } \\
\text { index }\end{array}$ & $\begin{array}{l}\text { Immunohis- } \\
\text { tochemistry }\end{array}$ \\
\hline [14] & Retrospective & 36 & Bite-on-bite & Large-capacity & $1 / 2.7$ & $42^{\S}$ & - & - \\
\hline [15] & Prospective & 23 & Bite-on-bite & $\begin{array}{l}\text { Large-capacity } \\
\text { Radial Jaw } 3\end{array}$ & No & $17^{\S}$ & - & - \\
\hline [16] & Retrospective & 24 & Bite-on-bite & Jumbo? & No & $25^{\dagger}$ & $?$ & + \\
\hline [17] & Prospective & 37 & Bite-on-bite & $\begin{array}{l}\text { Convention- } \\
\text { al-size } \\
\text { FB-25K-1 } \\
\end{array}$ & $5 / 14$ & 38 & - & - \\
\hline [18] & Retrospective & 22 & Bite-on-bite f $^{\ddagger}$ & $\begin{array}{c}\text { Jumbo } \\
\text { Radial Jaw } 4\end{array}$ & $5 / 22$ & 91 & $?$ & $?$ \\
\hline [19] & Retrospective & 129 & Bite-on-bite & $\begin{array}{c}\text { Jumbo } \\
\text { Radial Jaw } 4\end{array}$ & $45 / 35$ & $\begin{array}{l}59^{4} \\
65^{\S} \\
40^{\dagger} \\
\end{array}$ & - & - \\
\hline [20] & Case report & 4 & EUS-KB ${ }^{\varnothing}$ & $\begin{array}{l}\text { Convention- } \\
\text { al-size }\end{array}$ & No & $100 \%$ & + & + \\
\hline [21] & Prospective & 72 & $\begin{array}{l}\text { Jumbo biopsy } \\
\text { "unroofing" }\end{array}$ & $\begin{array}{c}\text { Jumbo } \\
\text { Radial Jaw } 4\end{array}$ & $1 / 1.3$ & $92 \%$ & $+(89 \%)$ & + \\
\hline [22] & Prospective & 16 & EPR-UT\& & $\begin{array}{l}\text { Partially resect- } \\
\text { ed by snaring }\end{array}$ & 9/56 (oozing) & $94 \%$ & $\begin{array}{l}+ \text { (in all } \\
\text { cases) }\end{array}$ & + \\
\hline [11] & Retrospective & 14 & $\mathrm{SINK}^{\Omega}$ & Radial Jaw 4 & No & $93 \%$ & $\begin{array}{c}+(71 \% \\
\text { of cases })\end{array}$ & + \\
\hline [12] & Retrospective & 27 & $M I A B^{\pi}$ & $\begin{array}{l}\text { Conventional } \\
\text { biopsy forceps }\end{array}$ & No & $85 \%$ & $\begin{array}{l}+ \text { (almost } \\
\text { in all } \\
\text { cases) }\end{array}$ & + \\
\hline [10] & Prospective & 9 & DB via ESD ${ }^{\Sigma}$ & $\begin{array}{c}\text { Standard } \\
\text { biopsy forceps } \\
\text { Radial Jaw } 3\end{array}$ & No & $100 \%$ & $\begin{array}{l}+ \text { (in all } \\
\text { cases) }\end{array}$ & + \\
\hline [1] & Prospective & 40 & DB via ESD ${ }^{\Sigma}$ & Radial Jaw 3 & No & $90 \%$ & + & + \\
\hline $\begin{array}{l}\text { Our } \\
\text { study }\end{array}$ & Prospective & 38 & DB via ESD ${ }^{\Sigma}$ & $\begin{array}{l}\text { Olympus } \\
\text { FB-50K-1 } \\
\text { FB-25K-1 }\end{array}$ & $\begin{array}{c}\text { Non-inten- } \\
\text { sive } 21 / 55.3 \% \\
\text { Intensive } \\
2 / 5.3 \% \\
\text { Perforation } \\
1 / 2.6 \%\end{array}$ & $\begin{array}{l}\text { 73\% over- } \\
\text { all 91\% } \\
\text { for clear } \\
\text { endophytic } \\
\text { lesions }\end{array}$ & $\begin{array}{l}+ \text { only in } \\
2 \text { cases } \\
\text { of } 9\end{array}$ & + \\
\hline
\end{tabular}

"Total diagnostic yield of bite-on-bite technique with jumbo biopsy forceps. ${ }^{\circledR}$ Diagnostic yield of bite-on-bite technique with jumbo biopsy forceps for subepithelial lesions from submucosa. ${ }^{\dagger}$ Diagnostic yield of bite-on-bite technique with jumbo biopsy forceps for subepithelial lesions from muscularis propria. ${ }^{\ddagger} B$ Biteon-bite technique with jumbo biopsy forceps and touch-preparation cytology. ${ }^{\circ} E U S$-guided keyhole biopsy technique. ${ }^{.} E P R$-UT endoscopic partial resection using the unroofing technique. ${ }^{\Omega} E U S$-guided single-incision with needle-knife (SINK) and deep forceps biopsies. ${ }^{\pi}$ Mucosal-incision assisted biopsy (MIAB), $\Sigma$ Deep biopsy via endoscopic submucosal dissection technique (DB via ESD). 
the retrospective and prospective studies the diagnostic yield of EUS-FNA and EUS-TCB ranges from $43 \%$ to $100 \%$ and from $53 \%$ to $82 \%$ in the latter [4]. These biopsy methods have become standard (especially EUS-FNA) for the acquisition of tissue from the SELS. However, some disadvantages do exist, such as an insufficient tissue sample for immunohistochemical $(\mathrm{IHC})$ staining and determining the mitotic index, especially for the evaluation of the malignant potential of the GIST [5-9].

Biopsies of SELS with the "bite-on-bite" technique in the most cases were non-diagnostic in our institution. Hence our aim was to determine the best option for the final pathological diagnosis of these SELS. Deep biopsy (DB) via endoscopic submucosal dissection (ESD) technique (DB via ESD) to the SEL was performed with a clear endophytic and not very prominent or exophytic shape. The overall diagnostic yield was $73.3 \%$, which is lower than in other studies [1, 10-12]. However, the diagnostic yield for SELS with the clear endophytic shape increased to $91.3 \%$.

No solution to the overlying layers of the SEL was injected before the incision. After the injection in some cases of SELS with a not very prominent shape, they became more flattening and it was difficult to locate an adequate incision location. This could have influenced the higher immediate non-intensive bleeding rate during biopsy in 21 (53.3\%) of 38 patients. Intensive bleeding occurred in 2 patients and perforation in 1 (the SEL had an exophytic growth pattern). In most cases the incision site was not fully closed with clips. In cases of persistent bleeding or its prevention, clipping or partial ligation of the SEL after the deep biopsy was used. The risk of possible delayed post-biopsy bleeding was also evaluated. Only in 2 cases were blood clots in the post-biopsy site without active bleeding spotted the next day after the procedure and overall no complications after 1 week were noted.

The GIST are the most common mesenchymal neoplasms in the gastrointestinal tract and are most commonly found in the stomach. To differentiate them from other SELs, immunohistochemical analysis is required. The risk of progression and metastases depends on GIST size, location, and mitotic rate [13]. According to Miettinen et al. the malignant risk of GISTs could be nonexistent, very low, low, moderate or high. In our study 9 cases of GISTs were diagnosed and 8 of them had surgical or combined surgical and ESD resection with en bloc specimens for a patho- logical examination. The tumor size was correctly determined during endoscopic ultrasound comparing it with the postoperative specimen size (Table V). In all cases an immunohistochemical analysis could be performed on the biopsy material. However, the overall size of the post-biopsy samples was insufficient in all cases to receive $50 \mathrm{HPF}$ high power fields (Tables IV, V) and to determine the true lesion risk preoperatively. It was possible to evaluate a mitotic index only in 2 cases (5 and 9). Nevertheless, the risk of lesions in the $9^{\text {th }}$ case was underscored with the mitotic rate of 2/50 HPF and with a very low risk after the deep biopsy, compared to the higher mitotic rate of 7/50 HPF and a moderate risk of disease progression after the resection. In the $5^{\text {th }}$ GIST the mitotic rate was 15/50 HPF. According to Miettinen and Lasota, it is a rare group of tumors with few cases and with probably $0 \%$ risk. Therefore, compared to other studies, our results in determining the GIST mitotic rate were lower (Table VI). The factors influencing this could be: first, too small size of the lesion ( $<15 \mathrm{~mm}$ in cases 3 and 6); second, the hard structure of the GIST made biopsy forceps glissade from the surface, and it was difficult to grasp the sample; and third, the type of biopsy forceps.

There are some limitations of the present study. Firstly, no comparison with other biopsy methods was made. Secondly, it was conducted in a single tertiary centre. Thirdly, most procedures were performed by one physician who had experience with ESD, and it is difficult to know what complication rate and what diagnostic yield would be achieved in other centers without such experience.

\section{Conclusions}

Deep biopsy via the ESD technique is an effective and safe method for the diagnosis of SELs especially with a clear endophytic appearance in a large number of biopsied samples. This technique successfully differentiates SELS, particularly leiomyomas, from GISTs; however, in most cases it is difficult to determine the true risk of the latter. The size of SELS was measured correctly with endoscopic ultrasound, comparing it with the sample size after the resection; however, the mitotic count from biopsy samples could be correctly made only in a few cases. SELS with not very prominent or exophytic shape depending on size, location, patient's age, life expectancy, comorbidities, and GIST possibility should be followed up or biopsied with other techniques; oth- 
erwise, if an SEL is hypoechogenic and/or larger than $>2 \mathrm{~cm}$ in the stomach, whether to directly perform a biopsy/excision with laparoscopic wedge resection is debatable.

\section{Conflict of interest}

The authors declare no conflict of interest.

\section{References}

1. Tae HJ, Lee HL, Lee KN, et al. Deep biopsy via endoscopic submucosal dissection in upper gastrointestinal subepithelial tumors: a prospective study. Endoscopy 2014; 46: 845-50.

2. Dumonceau JM, Polkowski M, Larghi A, et al. Indications, results, and clinical impact of endoscopic ultrasound (EUS)-guided sampling in gastroenterology: European Society of Gastrointestinal Endoscopy (ESGE) Clinical Guideline. Endoscopy 2011; 43: 897-912.

3. Gastrointestinal stromal tumours: ESMO Clinical Practice Guidelines for diagnosis, treatment and follow-up. Ann Oncol 2014; 25 Suppl. 3: iii21-6.

4. Eckardt AJ, Jenssen C. Current endoscopic ultrasound-guided approach to incidental subepithelial lesions: optimal or optional? Ann Gastroenterol 2015; 28: 160-72.

5. Philipper M, Hollerbach S, Gabbert HE, et al. Prospective comparison of endoscopic ultrasound-guided fine-needle aspiration and surgical histology in upper gastrointestinal submucosal tumors. Endoscopy 2010; 42: 300-5.

6. Eckardt AJ, Adler A, Gomes EM, et al. Endosonographic largebore biopsy of gastric subepithelial tumors: a prospective multicenter study. Eur J Gastroenterol Hepatol 2012; 24: 1135-44.

7. Polkowski M, Gerke W, Jarosz D, et al. Diagnostic yield and safety of endoscopic ultrasound-guided trucut [corrected] biopsy in patients with gastric submucosal tumors: a prospective study. Endoscopy 2009; 41: 329-34.

8. Fernandez-Esparrach G, Sendino O, Sole M, et al. Endoscopic ultrasound-guided fine-needle aspiration and trucut biopsy in the diagnosis of gastric stromal tumors: a randomized crossover study. Endoscopy 2010; 42: 292-9.

9. Lee JH, Choi KD, Kim MY, et al. Clinical impact of EUS-guided Trucut biopsy results on decision making for patients with gastric subepithelial tumors $>/=2 \mathrm{~cm}$ in diameter. Gastrointest Endosc 2011; 74: 1010-8.

10. Lee HL, Kwon OW, Lee KN, et al. Endoscopic histologic diagnosis of gastric Gl submucosal tumors via the endoscopic submucosal dissection technique. Gastrointest Endosc 2011; 74: 693-5.

11. de la Serna-Higuera C, Perez-Miranda M, Diez-Redondo P, et al. EUS-guided single-incision needle-knife biopsy: description and results of a new method for tissue sampling of subepithelial GI tumors (with video). Gastrointest Endosc 2011; 74: 672-6.

12. Ihara E, Matsuzaka H, Honda K, et al. Mucosal-incision assisted biopsy for suspected gastric gastrointestinal stromal tumors. World J Gastrointest Endosc 2013; 5: 191-6.

13. Miettinen M, Sobin LH, Lasota J. Gastrointestinal stromal tumors of the stomach: a clinicopathologic, immunohistochemi- cal, and molecular genetic study of 1765 cases with long-term follow-up. Am J Surg Pathol 2005; 29: 52-68.

14. Hunt GC, Smith PP, Faigel DO. Yield of tissue sampling for submucosal lesions evaluated by EUS. Gastrointest Endosc 2003; 57: 68-72.

15. Cantor MJ, Davila RE, Faigel DO. Yield of tissue sampling for subepithelial lesions evaluated by EUS: a comparison between forceps biopsies and endoscopic submucosal resection. Gastrointest Endosc 2006; 64: 29-34.

16. Hoda KM, Rodriguez SA, Faigel DO. EUS-guided sampling of suspected GI stromal tumors. Gastrointest Endosc 2009; 69: 1218-23.

17. Ji JS, Lee BI, Choi KY, et al. Diagnostic yield of tissue sampling using a bite-on-bite technique for incidental subepithelial lesions. Korean J Intern Med 2009; 24: 101-5.

18. Keswani RN, Nayar R, Mahajan A, et al. Touch preparation of jumbo forceps biopsies allows rapid adequacy assessment of subepithelial GI masses. Gastrointest Endosc 2011; 74: 411-4.

19. Buscaglia JM, Nagula S, Jayaraman V, et al. Diagnostic yield and safety of jumbo biopsy forceps in patients with subepithelial lesions of the upper and lower Gl tract. Gastrointest Endosc 2012; 75: 1147-52.

20. Grubel P. Keyhole biopsy: an easy and better alternative to fine-needle aspiration or Tru-cut biopsy of submucosal gastrointestinal tumors. Endoscopy 2010; 42: 685.

21. Komanduri S, Keefer L, Jakate S. Diagnostic yield of a novel jumbo biopsy "unroofing" technique for tissue acquisition of gastric submucosal masses. Endoscopy 2011; 43: 849-55.

22. Lee CK, Chung IK, Lee SH, et al. Endoscopic partial resection with the unroofing technique for reliable tissue diagnosis of upper Gl subepithelial tumors originating from the muscularis propria on EUS (with video). Gastrointest Endosc 2010; 71: 188-94.

Received: 22.04.2016, accepted: 4.07.2016. 